\title{
Phenotypic Variations and Heritability in Hybrid Populations of Bearded Iris
}

Zhuping Fan and Yike Gao ${ }^{1}$

Beijing Key Laboratory of Ornamental Plants Germplasm Innovation \& Molecular Breeding, National Engineering Research Center for Floriculture, School of Landscape Architecture, Beijing Forestry University, No.35 East Qinghua Road, Haidian District, Beijing, 100083, China

\section{Ling Guo and Ying Cao \\ Beijing Botanical Garden, Wofosi Road, Haidian District, Beijing, 100093, China}

\section{Rong Liu and Qixiang Zhang \\ Beijing Key Laboratory of Ornamental Plants Germplasm Innovation \& Molecular Breeding, National Engineering Research Center for Floriculture, School of Landscape Architecture, Beijing Forestry University, No.35 East Qinghua Road, Haidian District, Beijing, 100083, China}

Additional index words. bearded iris, phenotypic variation, heritability, trait correlation, flower color

\begin{abstract}
Bearded iris (Iris $\times$ hybrida Hort.) is a large horticultural hybrid complex in the Iris genus, and the lack of understanding about its inheritance laws has seriously hindered the breeding process. From parental bearded iris 'Indian Chief' and 'Sugar Blues', four hybrid populations-including $F_{1}, F_{2}, B C_{1} P_{1}$, and $B C_{1} P_{2}$-were generated through hybridization. Fifteen key phenotypic traits, including plant height (PH), scape height (SH), length of fall (LF), width of fall (WF), length of standard (LS), width of standard (WS), and so on, were measured, and several genetic parameters (e.g., trait variation, heritability, trait correlation, distribution of flower color) were analyzed. The variation of phenotypic traits indicated that the $F_{1}$ generation could produce larger flowers and a greater number of blooming stems than other generations, whereas backcrossing was beneficial at producing more flowers on one scape in the offspring of 'Indian Chief' and 'Sugar Blues'. WF had the greatest broad-sense heritability $(\mathbf{7 3 . 9 1 \% )}$ among the 15 phenotypic traits, whereas the broad-sense heritability of SH was the lowest $(2.06 \%)$. The correlation between a vegetative trait $(\mathrm{PH})$ and a reproductive trait (WS) provided a path to early selection of germplasm. Furthermore, four important floral traits (LF, WF, LS, and WS) also correlated significantly to each other, thus simplifying the selection of larger flowers. Genes regulating fuchsia flower color were dominant over those for bluish purple flowers. Genetic effects of flower color in recurrent parents could be reinforced by backcrossing, thereby providing a potential way to modify flower color through hybridization.
\end{abstract}

Bearded iris (Iris $\times$ hybrida Hort.), characterized by a thick and bushy "beard" on three falls (lower petals), refers to the large artificial hybrid population in the Iris genus.

\footnotetext{
Received for publication 15 Jan. 2019. Accepted for publication 19 Mar. 2019.

This research was supported by Graduate Training and Development Program of Beijing Municipal Commission of Education (BLCXY201801), as well as the National Natural Science Fund of China (no. 31770736).

We thank Yanchao Guo and Zhanhui Yang for helping us to establish the hybrid population. We thank Guobin Kou and Ximei Liu for the daily management of our plant materials. We also acknowledge Lu Meng, Yuxuan Cui, Yuhan Zhang, Saba Haider, and Martin Siaw for the language polishing of this paper.
}

${ }^{1}$ Corresponding author. E-mail: gaoyk@bjfu.edu.cn. research is important to investigate trait inheritance in bearded iris.

Heritability evaluation is one of the most fundamental steps in a breeding program to gain access to new genetic changes and to create new cultivars with specific traits (Azimi et al., 2018). Characteristics with high heritability can be useful for hybrid selection in iris breeding (Azimi et al., 2018). Over the past decades, researchers have carried out several studies about the trait inheritance in Iris related particularly to heritability. In candy lily (hybrids of I. dichotoma and I. domestica), the genetic variation of six traits was investigated and a high heritability of leaf width (55.95\%) was observed (Ruan et al., 2017). For I. pumila, the broad-sense heritability of 26 traits were evaluated and the floral traits were found to be less variable than vegetative traits (Tucic et al., 1990). Moreover, Azimi et al. (2018) evaluated the genetic differences among 43 hybrids produced by $I$. spuria and seven $I$. germanica cultivars, and a relatively high broad-sense heritability was observed for $\mathrm{PH}$, standard width, standard height, flower size, and leaf width (LW). In our previous research on bearded iris, WF and the number of flowers per scape (NFS) had the greatest broad-sense heritability $(91.47 \%)$ and strictsense heritability (53.96\%), respectively (Fan et al., 2017).

The previously mentioned studies have revealed the inheritance of phenotypic traits in Iris to some extent. However, previous research about phenotypic variation only included the $F_{1}$ generation, rather than investigating more offspring populations such as the $\mathrm{F}_{2}, \mathrm{BC}_{1} \mathrm{P}_{1}$, and $\mathrm{BC}_{1} \mathrm{P}_{2}$ generations. As a result, the conclusions drawn from the studies did not completely reflect the inheritance in bearded iris, thus hampering the breeding process (Anderson, 1996; Araujo et al., 2002; Tucic and Avramov, 1996). Therefore, comprehensive investigations of phenotypic traits in the $\mathrm{F}_{1}, \mathrm{~F}_{2}, \mathrm{BC}_{1} \mathrm{P}_{1}$, and $\mathrm{BC}_{1}$ $\mathrm{P}_{2}$ generations are clearly needed in iris breeding.

The bearded iris 'Indian Chief' [tall bearded (TB)] is one of the most popular and widely applied cultivars in China because of its velvety petals, ideal height, and strong resistance to root rot disease. 'Indian Chief' is usually chosen as the maternal parent in bearded iris breeding because of its poor pollen vigor and sparse pollen content in stamens (Austin, 2005). Another cultivar, Sugar Blues (TB), appears to be an ideal pollen donator (Fan et al., 2017).

In this research, four bearded iris offspring populations, including $\mathrm{F}_{1}, \mathrm{~F}_{2}, \mathrm{BC}_{1} \mathrm{P}_{1}$, and $\mathrm{BC}_{1} \mathrm{P}_{2}$, were generated through hybridization between 'Indian Chief' and 'Sugar Blues'. The objectives of this study were 1) to evaluate the variation of phenotypic traits, thus estimating the improvement of these traits over their parents; 2) to calculate the broad-sense heritability of the 15 tested traits to evaluate more completely the efficiency of direct selection; 3 ) to estimate the 
correlations between the tested phenotypic traits, making it possible to forecast the performance of certain traits by observing correlations and simplify the process of breeding; and 4) to analyze the proportion of flower colors in the offspring generations to generate more offspring with target flower colors.

\section{Materials and Methods}

Plant materials. In our study, 'Indian Chief' was selected as the maternal parent and 'Sugar Blues' was chosen to be the paternal parent. All the parents used in the hybridizations were inbred for three generations to guarantee homozygosity. The experimental materials were all cultivated in the Changping District of Beijing, China (lat. $40^{\circ} 09^{\prime} 15^{\prime \prime} \mathrm{N}$, long. $\left.116^{\circ} 27^{\prime} 44^{\prime \prime E}\right)$. All plant materials were provided with the same conditions with regard to soil, moisture, temperature, and light to avoid any influence from the external environment. The performance of the two parents are presented in Fig. 1.

Field experiment. The field experiment was conducted over 4 years, from 2013 to 2017 . The populations used in the hy-

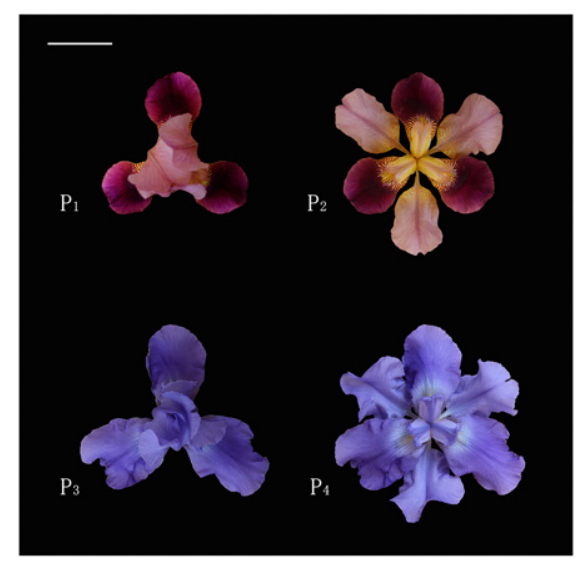

Fig. 1. The performances of two parents used in hybridization. $\mathrm{Bar}=5 \mathrm{~cm} . \mathrm{P}_{1}$ and $\mathrm{P}_{2}$, 'Indian Chief'. $\mathrm{P}_{3}$ and $\mathrm{P}_{4}$, 'Sugar Blues'. bridization program were distributed in a randomized complete block design, with three blocks in each population. To avoid contamination from other pollen, artificial emasculation was carried out the day before blooming, and the flowers were covered with bags after artificial emasculation. To make negative controls for each hybridization combination, 10 maternal individuals were covered with bags before flowering, but no seeds were generated.

In 2013, the $\mathrm{F}_{1}$ generation (including 565 individuals) was generated through the hybridization of 'Indian Chief' and 'Sugar Blues'. In 2015, the $F_{2}$ generation (including 286 individuals) was produced by the selfing of the $F_{1}$ generation. Furthermore, the $F_{1}$ hybrid generation was also used as the recurrent parent to backcross with 'Indian Chief' and 'Sugar Blues', respectively, thus generating the $\mathrm{BC}_{1} \mathrm{P}_{1}$ generation (including 296 individuals) and the $\mathrm{BC}_{1} \mathrm{P}_{2}$ generation (including 274 individuals).

During the blooming stage, 60 individuals were selected randomly from each generation, and 15 key ornamental traits [including $\mathrm{PH}, \mathrm{SH}$, leaf length (LL), LW, number of leaves per blooming stem (NLBS), number of leaves per nonblooming stem (NLNS), number of stems (NS), number of blooming stems (NBS), NFS, height of the individual flowers (HF), diameter of flowers (DF), LF, WF, LS, and WS] were measured to calculate genetic characteristics such as variation of phenotypic traits, heritability, and trait correlations. All measurements were carried out in triplicate for each plant. The flower color of each generation was also investigated during the blooming stage.

Characteristic measuring standard. $\mathrm{PH}$ represented the vertical distance from the soil level to the peak of the top leaf. $\mathrm{SH}$ was measured from the soil level to the top part of the plant, regardless of whether it contained leaves or standards. LL and LW referred to measurements of the longest leaf. HF was measured as the vertical distance between the fall's lowest part and the standard's highest part, and DF was measured as the largest parallel distance between two falls.

Statistical analysis. Broad-sense heritability was estimated as the ratio of total genotypic variance to the phenotypic variance, as described by Kelly and Bliss (1975):

$$
\mathrm{H}_{\mathrm{B}}=\frac{\mathrm{S}_{\mathrm{F} 2}^{2}-\left(\mathrm{S}_{\mathrm{P} 1}^{2}+\mathrm{S}_{\mathrm{P} 2}^{2}+\mathrm{S}_{\mathrm{F} 1}^{2}\right) / 3}{\mathrm{~S}_{\mathrm{F} 2}^{2}} \times 100,
$$

where $\mathrm{S}_{\mathrm{P} 1}^{2}, \mathrm{~S}_{\mathrm{P} 2}^{2}, \mathrm{~S}_{\mathrm{F} 1}^{2}$, and $\mathrm{S}_{\mathrm{F} 2}^{2}$ represent variances in the $\mathrm{P}_{1}, \mathrm{P}_{2}, \mathrm{~F}_{1}$, and $\mathrm{F}_{2}$ populations, and $\mathrm{H}_{\mathrm{B}}$ is broad-sense heritability.

Significant differences among various traits were tested with one-way analysis of variance using Duncan's new multiple range test in the SPSS software (ver. 22.0; IBM Corp., Armonk, NY). Correlations of phenotypic traits were examined using Pearson's correlation coefficient and the two-tailed significance test in the SPSS 22.0 software.

\section{Results and Discussion}

Variation of phenotypic traits. Knowledge of phenotypic characteristic variation, which indicates the amplitude in genetic variation of a characteristic under improvement, is very important for breeding programs (Santos et al., 2011).

In our breeding program, the $\mathrm{F}_{1}$ generation produced more blooming stems and larger flowers after the hybridization of 'Indian Chief' and 'Sugar Blues'. The largest phenotypic value for NBS (2.63) was obtained in the $F_{1}$ generation, and the phenotypic values of the floral traits (LF, WF, WS) were the largest in the $\mathrm{F}_{1}$ generation as well (Table 1). However, the $\mathrm{F}_{2}$ generation had the smallest phenotypic value for the floral traits LF and WF, leading to smaller flowers and reduced aesthetic values.

The two backcross generations of 'Indian Chief' and 'Sugar Blues', $\mathrm{BC}_{1} \mathrm{P}_{1}$ and $\mathrm{BC}_{1} \mathrm{P}_{2}$, could produce more flowers, whereas selfing was not helpful for producing more flowers on one scape. For NFS, $\mathrm{BC}_{1} \mathrm{P}_{1}$ and $\mathrm{BC}_{1} \mathrm{P}_{2}$

Table 1. Phenotypic values of the tested 15 traits in the maternal parent, paternal parent, $\mathrm{F}_{1}, \mathrm{~F}_{2}, \mathrm{BC}_{1} \mathrm{P}_{1}$, and $\mathrm{BC}_{1} \mathrm{P}_{2}$ generations.

\begin{tabular}{|c|c|c|c|c|c|c|}
\hline Phenotypic traits & Maternal parent & Paternal parent & $\mathrm{F}_{1}$ & $\mathrm{~F}_{2}$ & $\mathrm{BC}_{1} \mathrm{P}_{1}$ & $\mathrm{BC}_{1} \mathrm{P}_{2}$ \\
\hline$\overline{\mathrm{PH}}(\mathrm{cm})$ & $59.29 \pm 6.33 \mathrm{a}$ & $47.33 \pm 6.01 \mathrm{c}$ & $56.19 \pm 7.11 \mathrm{ab}$ & $45.92 \pm 7.64 \mathrm{c}$ & $51.88 \pm 6.19 b c$ & $46.43 \pm 7.44 \mathrm{c}$ \\
\hline $\mathrm{SH}(\mathrm{cm})$ & $82.99 \pm 5.16 \mathrm{a}$ & $84.00 \pm 6.87 \mathrm{a}$ & $80.22 \pm 5.52 a$ & $63.08 \pm 5.96 b$ & $64.45 \pm 13.10 b$ & $64.05 \pm 11.54 b$ \\
\hline $\mathrm{LL}(\mathrm{cm})$ & $59.51 \pm 4.87 \mathrm{a}$ & $54.00 \pm 5.76 \mathrm{abc}$ & $56.28 \pm 7.91 \mathrm{ab}$ & $46.91 \pm 7.96 \mathrm{c}$ & $51.48 \pm 6.79 \mathrm{bc}$ & $46.83 \pm 6.22 \mathrm{c}$ \\
\hline $\mathrm{LW}(\mathrm{cm})$ & $4.28 \pm 0.40 \mathrm{a}$ & $3.17 \pm 0.24 \mathrm{bcd}$ & $3.57 \pm 0.35 \mathrm{~b}$ & $2.71 \pm 0.37 \mathrm{~d}$ & $3.37 \pm 0.81 \mathrm{bc}$ & $2.87 \pm 0.61 \mathrm{~cd}$ \\
\hline NLBS & $3.10 \pm 0.54 \mathrm{ab}$ & $3.33 \pm 0.57 \mathrm{a}$ & $2.27 \pm 0.58 \mathrm{c}$ & $2.25 \pm 0.62 \mathrm{c}$ & $2.53 \pm 0.87 \mathrm{bc}$ & $2.47 \pm 0.74 b c$ \\
\hline NLNS & $5.80 \pm 0.63 \mathrm{a}$ & $5.67 \pm 0.57 \mathrm{a}$ & $5.00 \pm 0.75 \mathrm{a}$ & $5.00 \pm 0.85 \mathrm{a}$ & $5.29 \pm 0.77 \mathrm{a}$ & $5.40 \pm 0.83 \mathrm{a}$ \\
\hline NS & $14.20 \pm 2.53 \mathrm{a}$ & $4.67 \pm 2.08 \mathrm{~b}$ & $12.60 \pm 1.83 \mathrm{a}$ & $7.58 \pm 2.50 \mathrm{~b}$ & $8.18 \pm 3.26 b$ & $6.53 \pm 3.31 \mathrm{~b}$ \\
\hline NBS & $2.10 \pm 0.62 \mathrm{ab}$ & $1.33 \pm 0.57 b$ & $2.63 \pm 0.66 \mathrm{a}$ & $1.17 \pm 0.67 \mathrm{~b}$ & $1.41 \pm 0.80 \mathrm{~b}$ & $1.33 \pm 0.62 \mathrm{~b}$ \\
\hline NFS & $5.60 \pm 0.66 \mathrm{ab}$ & $5.67 \pm 0.57 \mathrm{ab}$ & $4.47 \pm 0.47 \mathrm{~b}$ & $3.92 \pm 0.67 b$ & $5.88 \pm 0.70 \mathrm{a}$ & $5.93 \pm 0.70 \mathrm{a}$ \\
\hline $\mathrm{HF}(\mathrm{cm})$ & $12.20 \pm 0.67 \mathrm{a}$ & $11.33 \pm 0.81 \mathrm{a}$ & $12.20 \pm 0.74 \mathrm{a}$ & $10.94 \pm 0.98 \mathrm{a}$ & $10.67 \pm 1.55 \mathrm{a}$ & $11.32 \pm 1.44 \mathrm{a}$ \\
\hline $\mathrm{DF}(\mathrm{cm})$ & $11.38 \pm 1.45 b$ & $14.70 \pm 0.89 \mathrm{a}$ & $12.00 \pm 1.77 b$ & $10.58 \pm 1.97 b$ & $11.31 \pm 1.57 \mathrm{~b}$ & $11.39 \pm 2.13 b$ \\
\hline $\mathrm{LF}(\mathrm{cm})$ & $8.71 \pm 0.53 \mathrm{a}$ & $8.70 \pm 0.46 \mathrm{a}$ & $8.88 \pm 0.52 \mathrm{a}$ & $7.62 \pm 0.79 b$ & $8.03 \pm 0.79 \mathrm{ab}$ & $8.59 \pm 1.21 \mathrm{ab}$ \\
\hline $\mathrm{WF}(\mathrm{cm})$ & $5.21 \pm 0.35 \mathrm{bc}$ & $6.20 \pm 0.28 \mathrm{a}$ & $5.99 \pm 0.39 \mathrm{a}$ & $4.73 \pm 0.68 \mathrm{c}$ & $5.17 \pm 0.69 \mathrm{bc}$ & $5.51 \pm 0.75 \mathrm{ab}$ \\
\hline $\mathrm{LS}(\mathrm{cm})$ & $8.53 \pm 0.49 a$ & $7.80 \pm 0.56 \mathrm{a}$ & $8.56 \pm 0.77 \mathrm{a}$ & $7.61 \pm 0.78 \mathrm{a}$ & $7.92 \pm 0.74 \mathrm{a}$ & $8.34 \pm 1.22 \mathrm{a}$ \\
\hline $\mathrm{WS}(\mathrm{cm})$ & $5.64 \pm 0.32 \mathrm{a}$ & $5.80 \pm 0.30 \mathrm{a}$ & $6.12 \pm 0.44 \mathrm{a}$ & $5.44 \pm 0.49 b$ & $5.53 \pm 0.68 b$ & $5.55 \pm 0.78 b$ \\
\hline
\end{tabular}

Statistics were collected from 60 random individuals in each population. Different letters within the same row indicate significant differences $(P<0.05)$.

$\mathrm{PH}=$ plant height; $\mathrm{SH}=$ scape height; $\mathrm{LL}=$ leaf length; $\mathrm{LW}=$ leaf width; NLBS = number of leaves per blooming stem; NLNS = number of leaves per nonblooming stem; NS = number of stems; NBS = number of blooming stems; NFS = number of flowers per scape; HF = height of individual flowers; DF = diameter of flowers; $\mathrm{LF}=$ length of fall; $\mathrm{WF}=$ width of fall; $\mathrm{LS}=$ length of standard; $\mathrm{WS}=$ width of standard. 
produced more flowers on one scape (NFS = 5.88 and NFS $=5.93$, respectively) than 'Indian Chief' and 'Sugar Blues' (NFS = 5.60 and NFS $=5.67$, respectively). However, NFS of the $F_{1}$ generation (4.47) and the $\mathrm{F}_{2}$ generation (3.92) was less than their parents.

Backcrossing was first proposed for developing crop plants (Harlan and Pope, 1922). Now it has been commonly applied in breeding programs and has accelerated the development of horticultural research. After conducting one round of backcrossing, a portion of the resulting progeny could obtain the phenotypic integrity of one parent and the desirable genetics of the other, which provides an effective and inexpensive way to introduce desirable trait into the preferred genetic background (Vogel, 2009). Breeders can enhance certain target traits from one parent by using the latter as the recurrent parent, thus accelerating the genetic effect introgression into the progeny (Austin, 2005).

Broad-sense heritability of phenotypic traits. If the heritability value is very small or close to zero, there is no genetic variability, and the differences among individuals are likely a result of environmental factors (Falconer, 1989). According to the classification method proposed by Fogaca et al. (2012), heritability at an individual level can be considered low when it is less than 0.15 ; medium, when between 0.15 and 0.50 ; and high, when greater than 0.50 . Traits with high heritability, considerable phenotypic correlation, and low seasonal variability can be candidates for further improvement (Sabu et al., 2009).

In our research, WF had the greatest broad-sense heritability $(73.91 \%)$, whereas the broad-sense heritability of SH was the least $(2.06 \%)$ (Table 2$)$. The greatest broadsense heritability of WF indicates the ambient environment exerted little influence on the inheritance of WF, and this trait can be improved by consecutive hybridization. This conclusion was consistent with our previous research on bearded iris (Fan et al., 2017), which also showed the greatest heritability of WF among all tested traits. In contrast, the least broad-sense heritability of $\mathrm{SH}$ indicated greater influence from the external environment and that the appropriate environment could lead to promotion of $\mathrm{SH}$.

In the research of hybrids within I. germanica, as well as hybrids between I. germanica and I. spuria, the heritability of fall width $(78 \%)$ was similar to our result (73.91\%) (Azimi et al., 2018). However, the heritability of $\mathrm{PH}$ and $\mathrm{SH}$ in the study by Azimi et al. (2018) was greater than ours. The reason may be that their research was conducted on $\mathrm{F}_{1}$ hybrids of $I$. germanica and $I$. spuria, whereas ours focused on $\mathrm{F}_{1}, \mathrm{~F}_{2}, \mathrm{BC}_{1} \mathrm{P}_{1}$, and $\mathrm{BC}_{1} \mathrm{P}_{2}$ hybrids from different cultivars.

Moreover, in our study the broad-sense heritability of six floral traits (HF, DF, LF, $\mathrm{WF}, \mathrm{LS}$, and WS) were all greater than other measured traits except NLNS. There- fore, these six floral traits could be passed down more easily from 'Indian Chief' and 'Sugar Blues' to their progeny, and hence parents with desirable floral traits were more likely to produce offspring with desirable flowers.

Phenotypic trait correlations. Correlation between traits is an indispensable parameter to estimate whether the selection for one trait will have an influence on another (Majidi et al., 2009; Yu, 1989). It is usually difficult to select traits controlled by more than one gene; therefore, the analysis of correlations between different phenotypic traits is essential for a breeding program.

In the offspring of 'Indian Chief' and 'Sugar Blues', significant correlations exist among vegetative traits. An important vegetative trait, $\mathrm{PH}$, had significant correlations with other vegetative traits such as LL and NLNS (Table 3). Therefore, taller offspring would theoretically produce more and longer leaves on nonblooming stems. Similarly, a significant correlation between $\mathrm{PH}$ and LW has also been detected in $I$. germanica (Azimi et al., 2018).

Significant phenotypic correlations also occurred between reproductive traits. The crucial reproductive trait $\mathrm{SH}$ tended to be related significantly to other reproductive traits such as NBS and NFS (Table 3). It can be hypothesized that individuals with taller scapes were likely to produce more blooming stems and more flowers on one scape, thus improving aesthetic value during the blooming stage. Similar results came from research that claimed a significant correlation between $\mathrm{SH}$ and flower size (Azimi et al., 2018). With regard to floral traits, HF, DF, LF, WF, LS, and WS correlated significantly with each other. The correlation coefficients between LF, WF, LS, and WS were all greater than 0.7 . Therefore, breeders can measure some complex traits indirectly by evaluating the correlation between simple traits (Azimi et al., 2012; Soltani et al., 2010).

Some correlations existed between vegetative and reproductive traits, making it possible for early selection. The vegetative trait $\mathrm{PH}$ was associated significantly with the reproductive trait WS (Table 3), suggesting that taller individuals may produce wider standards. According to this correlation, iris breeders could select individuals with wider falls in advance by choosing the taller plants during vegetative growth. The correlations between vegetative and productive traits have also occurred in other species within Iridaceae, such as Crocus sativus (Baghalian et al., 2010): two traits (flower number and leaf number), with high heritability and ease of measurement, were highly correlated with an important quantitative trait (dry stigma weight) and two qualitative traits (picrocrocin and safranal content). The correlations between easyto-observe and difficult-to-observe traits allow for easy field screening and can be efficient indicators for germplasm selection and evaluation.

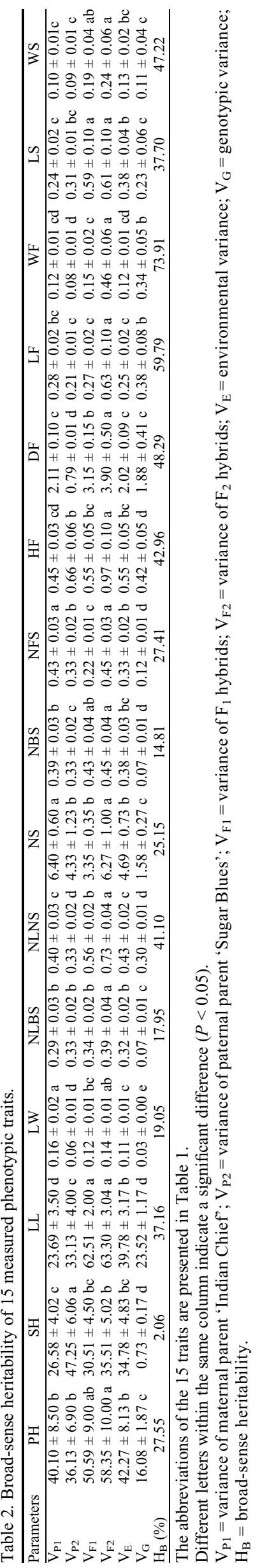

HortScience Vol. 54(6) June 2019 
However, significant negative correlations occurred between NLBS and NFS (Table 3), showing a tendency toward more leaves on a blooming stem leading to fewer flowers on one scape. More leaves on a blooming stem may consume a larger amount of nutrients during the vegetative growth stage, thus rendering the plant unable to support more flowers on a scape. Negative phenotypic correlations also occurred in lisianthus (Eustoma grandiflorum), such that days to flowering correlated negatively with number of nodes and node length (Ecker et al., 1994).

Variation in flower color. In our breeding program, progeny derived from 'Indian Chief' and 'Sugar Blues' mainly produced three flower colors: bluish purple, purple, and fuchsia (Fig. 2). The flower color of the maternal parent 'Indian Chief' was fuchsia, whereas the paternal parent 'Sugar Blues' was bluish purple. The intermediate color between fuchsia and bluish purple was purple, which was generated by hybridization between the two parents.

Genetic effects of flower color can be reinforced by backcrossing to a recurrent parent, thus providing breeders a way to modify the flower color of hybrids. In our research, all individuals in the $F_{1}$ generation had purple flowers (Fig. 3). However, the flower color became more diverse after the selfing of the $F_{1}$ generation. In the $F_{2}$ generation, $49.41 \%$ of the progeny had fuchsia flowers, whereas $30.95 \%$ had purple flowers and $19.64 \%$ had bluish purple ones. When 'Indian Chief' was used in a backcross program as the recurrent parent, its genetic effect of being fuchsia was enhanced to $64.29 \%$ in the $\mathrm{BC}_{1} \mathrm{P}_{1}$ generation. On the other hand, when the recurrent parent was 'Sugar Blues', its genetic effect was enhanced in the $\mathrm{BC}_{1} \mathrm{P}_{2}$ generation. Nearly $33.93 \%$ of this popula- tion had bluish purple flowers, and this percentage was the greatest among the four offspring generations. Backcrossing can reinforce the genetic effects of recurrent parents, and progeny thus becomes similar to a recurrent parent through consecutive backcrossing (Austin, 2005; Stebbins, 1950).

The high percentage of fuchsia flowers in hybrid populations may be the result of the possibility that genes regulating fuchsia flower color were dominant over those regulating bluish purple flowers in bearded iris. This is supported by the fact that most irises in nature have fuchsia flowers (Austin, 2005), but further experiments are needed to confirm this hypothesis. Some molecular research has been carried out in the I. germanica pink cultivar Fire Bride. For example, the ectopic expression of the $\operatorname{crtB}$ gene caused several flower parts to appear in different degrees of novel orange and pink

Table 3. Phenotypic trait correlations for the 15 tested phenotypic traits of bearded iris.

\begin{tabular}{|c|c|c|c|c|c|c|c|c|c|c|c|c|c|c|c|}
\hline Phenotypic traits & $\mathrm{PH}$ & SH & LL & LW & NLBS & NLNS & NS & NBS & NFS & $\mathrm{HF}$ & $\overline{\mathrm{DF}}$ & LF & WF & LS & WS \\
\hline$\overline{\mathrm{PH}}$ & - & 0.241 & $0.850^{* *}$ & 0.261 & 0.049 & $0.377^{*}$ & -0.004 & 0.065 & 0.087 & 0.203 & 0.147 & 0.204 & 0.228 & 0.166 & $0.375^{*}$ \\
\hline LL & - & - & - & $0.417 *$ & 0.207 & $0.390 *$ & -0.141 & 0.012 & 0.068 & 0.285 & 0.285 & $0.374 *$ & 0.308 & 0.318 & $0.471 * *$ \\
\hline LW & - & - & - & - & 0.269 & $0.471^{* *}$ & -0.172 & -0.020 & -0.173 & 0.188 & 0.051 & 0.205 & 0.343 & 0.242 & $0.387^{*}$ \\
\hline ILNS & - & - & - & - & - & - & -0.206 & -0.293 & -0.118 & -0.116 & -0.165 & -0.035 & -0.009 & -0.008 & 0.128 \\
\hline NS & - & - & - & - & - & - & - & $0.684 * *$ & 0.256 & -0.045 & -0.089 & -0.031 & -0.116 & -0.035 & -0.161 \\
\hline NBS & - & - & - & - & - & - & - & - & 0.200 & 0.174 & -0.117 & 0.178 & 0.123 & 0.177 & 0.110 \\
\hline DF & - & - & - & - & - & - & - & - & - & - & - & $0.633 * *$ & $0.694 * *$ & $0.631 * *$ & $0.568 * *$ \\
\hline LF & - & - & - & - & - & - & - & - & - & - & - & - & $0.821^{* *}$ & $0.958 * *$ & $0.800^{* *}$ \\
\hline WF & - & - & - & - & - & - & - & - & - & - & - & - & - & $0.842 * *$ & $0.861^{* *}$ \\
\hline LS & - & - & - & - & - & - & - & - & - & - & - & - & - & - & $0.815^{* *}$ \\
\hline WS & - & - & - & - & - & - & - & - & - & - & - & - & - & - & - \\
\hline
\end{tabular}

*,**Means correlation significant at $P \leq 0.05$ or 0.01 , respectively.

The abbreviations of the 15 traits are presented in Table 1 .

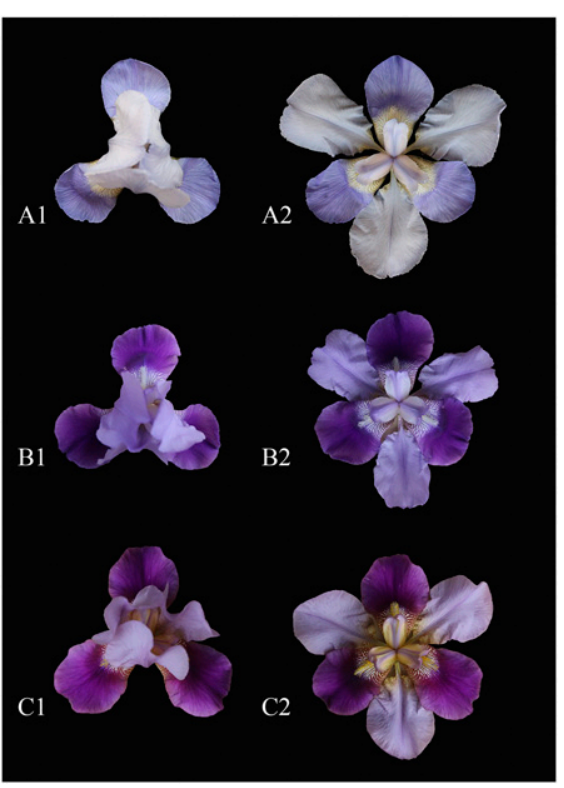

Fig. 2. The performance of three floral colors. $A_{1}$ and $A_{2}$, bluish purple. $B_{1}$ and $B_{2}$, purple. $C_{1}$ and $\mathrm{C}_{2}$, fuchsia.
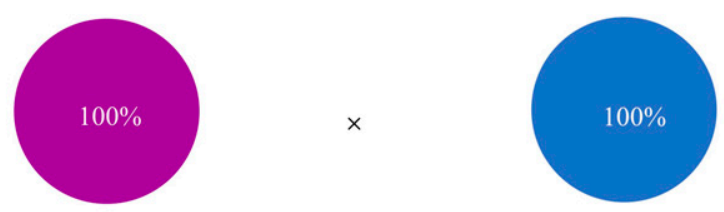

I. 'Indian Chief'

I. 'Sugar Blues'
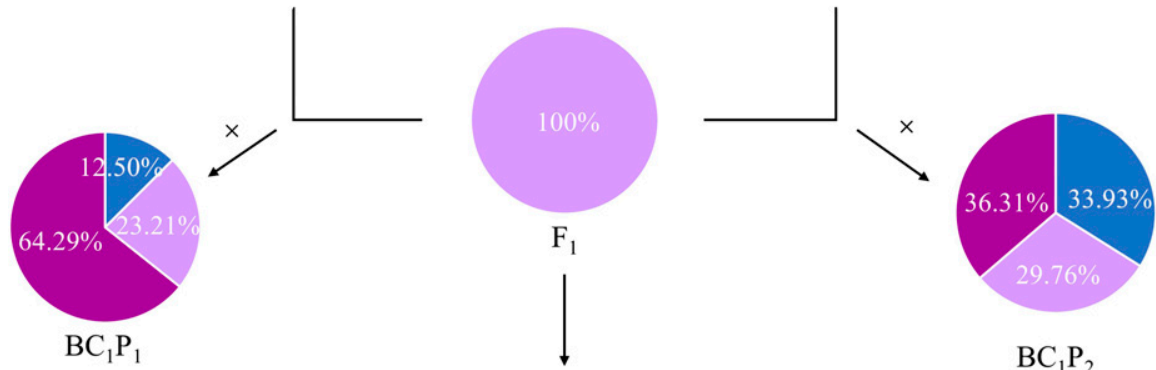

$\mathrm{BC}_{1} \mathrm{P}_{2}$

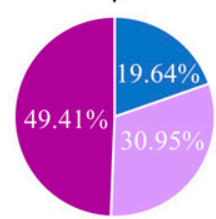

$\mathrm{F}_{2}$

Fig. 3. The distribution of floral colors in the $\mathrm{F}_{1}, \mathrm{~F}_{2}, \mathrm{BC}_{1} \mathrm{P}_{1}$, and $\mathrm{BC}_{1} \mathrm{P}_{2}$ generations. 
colors, but it failed to generate red flowers (Jeknic et al., 2014).

\section{Conclusion}

Four progeny populations derived from 'Indian Chief' and 'Sugar Blues' were constructed, including $\mathrm{F}_{1}, \mathrm{~F}_{2}, \mathrm{BC}_{1} \mathrm{P}_{1}$, and $\mathrm{BC}_{1}$ $\mathrm{P}_{2}$, which was the first indispensable step toward further research on the phenotypic trait inheritance of bearded iris. $F_{1}$ had the greatest phenotypic values for the traits LF, WF, WS, and NBS, whereas the phenotypic values of $\mathrm{F}_{2}$ were much less, indicating that selfing was not helpful for generating larger flowers with more blooming stems. Furthermore, the backcross generations produced more flowers on a scape than other generations. WF had the greatest broad-sense heritability (73.91\%) among all the tested traits, thereby indicating that direct selection of this trait is useful. SH had the least broad-sense heritability $(2.06 \%)$ as a result of the influence of the external environment. Interestingly, the heritability of six floral traits was greater than the other traits except NLNS, indicating that the external environment likely exerted little influence on flower size. Correlations between a vegetative trait $(\mathrm{PH})$ and a reproductive trait (WS) provided a possibility for forecasting individuals with wider standards by selecting taller ones at the seedling stage. Four key floral traits (LF, WF, LS, and WS) correlated significantly to each other; therefore, individuals with larger falls would theoretically obtain larger standards, which could simplify the selection of flower size. With respect to flower color, the genes for fuchsia flowers were dominant over those for bluish purple flowers, and the genetic effect of flower color could be reinforced by using a recurrent parent in a backcross generation. Although some preliminary genetic laws have been observed in this research, the in-depth mechanisms of bearded iris trait inheritance remain unclear as a result of the lack of further experiments at the molecular level. Future investigations are strongly recommended to improve understanding about the genetics of bearded iris.

\section{Literature Cited}

Anderson, S. 1996. Floral variation in Saxifraga granulata: Phenotypic selection, quantitative genetics and predicted response to selection. Heredity 77(4):217-223.

Araujo, M.R.A., B.E. Coulman, and G. Rakow. 2002. Genetic variation, heritability and progeny testing in meadow bromegrass. Plant Breed. 121(5):417-424.

Austin, C. 2005. Irises: A gardener's encyclopedia. Timber Press, Portland, OR.

Azimi, M.H., S. Jozghasemi, and R. Barba-Gonzalez. 2018. Multivariate analysis of morphological characteristics in Iris germanica hybrids. Euphytica 214(9): 161.

Azimi, M.H., S.Y. Sadeghian, V.R. Ahari, F. Khazaei, and A.F. Hafashjani. 2012. Genetic variation of Iranian iris species using morphological characteristics and RAPD markers. Intl. J. Agrisci. 2(9):571-580.

Baghalian, K., M.S. Sheshtamand, and A.H. Jamshidi. 2010. Genetic variation and heritability of agromorphological and phytochemical traits in Iranian saffron (Crocus sativus L.) populations. Ind. Crops Prod. 31(2):401-406.

Ecker, R., A. Barzilay, and E. Osherenko. 1994. Population means and correlation analyses of growth parameters in lisianthus (Eustoma grandiflorum Shinn.). Euphytica 78(3):193-197.

Falconer, D.S. 1989. Introduction to quantitative genetics, 3rd ed. Longman, New York, NY.

Fan, Z.P., Y.K. Gao, Y.C. Guo, R. Liu, and Q.X. Zhang. 2017. Phenotypic variations and heritability of bearded iris breeding. Euphytica 213(11):252-262.

Fogaca, L.A., R.A. Oliveira, F.L. Cuquel, J.C.B. Filho, W.A. Vendrame, and A.F.C. Tombolato. 2012. Heritability and genetic correlation in daylily selection. Euphytica 184(3):301-310.

Guo, L. 2000. Iris. Shanghai Science and Technology Press, Shanghai, China (in Chinese).

Harkess, R.L., M. Zhang, and D. Cochran. 2010. Cool night temperatures stimulate floral initiation in tall bearded iris. HortScience 45:S296-S297.

Harlan, H.V. and M.N. Pope. 1922. The use and value of back-crosses in small-grain breeding. J. Hered. 13:319-322.

Jeknic, Z., S. Jeknic, S. Jevremovic, A. Subotic, and T.H.H. Chen. 2014. Alteration of flower color in Iris germanica L. 'Fire Bride' through ectopic expression of phytoene synthase gene (crtB) from Pantoea agglomerans. Plant Cell Rep. 33(8):1307-1321.

Kelly, J.D. and F.A. Bliss. 1975. Heritability estimates of percentage seed protein and available methionine and correlations with yield in dry beans. Crop Sci. 15(6):753-757.
Li, D.Q., G.Q. Wang, K. Li, J.P. Zhang, and Y.P. Xia. 2016. Effects of chlorocholine chloride and prohexadione-Ca on rhizome growth and lateral bud production in Iris germanica L. J. Hort. Sci. Biotechnol. 91(4):396-403.

Majidi, M.M., A. Mirlohi, and F. Amini. 2009. Genetic variation, heritability and correlations of agro-morphological traits in tall fescue (Festuca arundinacea Schreb.). Euphytica 167(3):323-331.

Ruan, L.L., Y.K. Gao, Q. Wu, M. Fu, Z.H. Yang, and Q.X. Zhang. 2017. An analysis of the genetic variation in ornamental traits in hybrids of Iris dichotoma and I. domestica. Euphytica 213(1):8.

Sabu, K.K., M.Z. Abdullah, L.S. Lim, and R. Wickneswari. 2009. Analysis of heritability and genetic variability of agronomically important traits in Oryza sativa $\times$ O. rufipogon cross. Agron. Res. 7(1):97-102.

Santos, E.A., M.M. Souza, A.P. Viana, A.A.F. Almeida, J.C.O. Freitas, and P.R. Lawinscky. 2011. Multivariate analysis of morphological characteristics of two species of passion flower with ornamental potential and of hybrids between them. Genet. Mol. Res. 10(4):2457-2471.

Soltani, F., Y. Akashi, A. Kashi, Z. Zamani, Y. Mostofi, and K. Kato. 2010. Characterization of Iranian melon landraces of Cucumis melo L. Groups Flexuosus and Dudaim by analysis of morphological characters and random amplified polymorphic DNA. Breed. Sci. 60:34-45.

Stebbins, G.L. 1950. Variation and evolution in plants. Columbia University Press, New York, NY.

The American Iris Society. 1978. The world of irises. The American Iris Society, Molalla, OR.

Tucic, B. and S. Avramov. 1996. Maternal effects on early juvenile traits in Iris pumila (Iridaceae). Plant Syst. Evol. 201(1):179-197.

Tucic, B., A. Tarasjev, S. Vujcic, S. Milokovic, and N. Tucic. 1990. Phenotypic plasticity and character differentiation in a subdivided population of Iris pumila (Iridaceae). Plant Syst. Evol. 170(1):1-9.

Vogel, K.E. 2009. Backcross breeding. Methods Mol. Biol. 526:161-169.

Yu, Y. 1989. Correlation and selection responses of flowering time with other traits in the Davis population of gerbera. University of California, Davis, MS thesis.

Zhao, X.J., G.H. Bi, R.L. Harkess, J.J. Varco, and E.K. Blythe. 2016. Spring nitrogen uptake, use efficiency, and partitioning for growth in Iris germanica 'Immortality'. HortScience 51:563-566. 